\title{
The Pandemic of Opioids: A South Asian Public Health Perspective
}

1. Dattatreya Mukherjee, 5th year MBBS Student, International School, Jinan University, Guangzhou, P.R China, Email: dattatreyamukheriee4u@outlook.com

2. Shahzeb Ali Memon, 3rd Year MBBS Student, Dow Medical College, Dow University of Health Sciences, Karachi, Pakistan. Email: shahzeb.ali101@outlook.com

3. Sameer Saleem Tebha, 4th year MBBS Student, Department of Neurosurgery, Jinnah Medical and Dental College (JMDC), Karachi, Pakistan, Email: samtebha@gmail.com

\section{Corresponding Author: Dattatreya Mukherjee, dattatreyamukherjee4u@outlook.com}

Conflict of Interest: Authors don't have any COI

Funding: This work is not funded

Author's contribution: All the authors contributed equally

Opioids are accepted as appropriate and legitimate pain relief agents when prescribed for pain moderation but are associated with a high degree of abuse resulting in deaths from misuse, violence, diversion, addiction, and overdose. Ranging from classic drugs like the infamous morphine or Vicodin to new drugs like Fentanyl, opioids have shown an upward trend in use, abuse, growth, and seizing every successive year. Around $2 \%$ of the South Asian population used some form of opioid as of $2018 .^{1}$

"Death for 50 Rupees' - this is what photographer Enrico Fabian calls his photographic work. His clear black and white photos from Jahangirpuri, a settlement in New Delhi, India, bear witness to a bleak reality: the abuse of prescription opioids and psychotropic substances. Cracking down on opioid use has been lackluster, in particular in South Asia, despite foreign and national legislation laws. Opioids, amphetamines, and cocaine are the most common types of illicit drugs used in the region. According to WHO figures, over $70 \%$ of the worldwide drug use deaths are attributable to opioids ${ }^{2}$. Mortality from overdoses is not the only adverse public health result 
associated with the increased use of Opioid Pain Reliever (OPR), the increase in opioid use has also been linked with a dramatic rise in non-medical OPR emergency department visits. There was a 900 percent increase in people seeking treatment for addiction to OPRs between 1997 and 2011. 3,4 The intravenous (IV) use of drugs, such as heroin, can easily cause drug overdose as supported by a systematic review that shows one out of five IV drug users die of an overdose ${ }^{5}$. The use of these drugs also increases the disease burden of blood-borne diseases like HIV, HCV amongst many others. Abuse of Tapentadol, an over-the-counter pain medication, has become commonplace in India. Nearly 1.6 million Pakistanis were found to misuse prescription opioids for non-medical purposes ${ }^{6}$. Pakistan is one of the top 10 countries where citizens use both prescription and non-prescribed narcotics and opiates, reported by the United Nations Office on Drugs and Violence ${ }^{7}$. More people have died in Pakistan from opioids than heroin and cocaine. The study of Zainab Majib ${ }^{6}$ shows that the majority of opioids are prescribed against chronic pain in Karachi, Pakistan. The dosages are given on the basis of pain scale and sometimes opioids level of the Urine. A significant problem to be highlighted in this paper is the marketing and promotional strategies employed by pharmaceutical companies. Due to these promotions, people are getting false information and as well as easy access to opioid drugs. According to the Government of India report, the prevalence of opioid misuse is as high as $2.1 \%$ of the total population ${ }^{8}$. A grim situation looms over other South-Asian countries like Bangladesh, Sri Lanka where drug abuse has increased needle-based blood-borne disease transmissions like HIV and HBV. These situations mostly happen due to the usage of the same non-sterilized syringes among many individuals. In order to stop this serious condition, awareness is needed, the open markets of the opioids should be closed, and as well as the needle exchange programs should be closed. $^{9}$

Opioid overdose is a severe problem that is often fatal. It affects the blood circulation in the brain, affects the ionotropic and chronotropic functions of the heart, and thus causes death most of the time. A variety of variables placed a person at risk of opioid overdose, including addiction, substance purity, alcohol and opioid mixing, poor health, depression, drug shortage, etc. According to the United Nations Office on Drug Crime, in Mizoram, India, 65 percent of overdose cases were found to have taken place at home or at a friend's place. It is also important to inform opioid consumers, their colleagues, and medical professionals on the prevention and 
treatment of overdose, so that overdose and its related harms, including death, can be easily prevented. Pharmacoepidemiological monitoring may offer a clearer picture of the level of overdose and assistance target programs, leveraging reports from medical examiners, emergency medical providers, hospitals, overdose control programs, and law enforcement.

The young generation is the one most at risk. Nonmedical use of opioids is common in the 15 to 24 years age bracket and the majority of opioid overdose-related deaths occur in the age bracket of 45-54 years. Due to this mis usage, crime rates are on the rise in these countries; with stealing, rape, and other vices becoming a common sight due to the influence of opioids.

This is only the tip of the iceberg. The abuse of drugs is closely related to psychological factors, education, and weak laws. One study state that positive psychological interventions can reduce the risk of opioid misuse ${ }^{10}$. Proper psychological counselling is required. For those stuck in this addiction, proper rehab centres and programs should be set up to give them a chance to get clean. Lack of education regarding these drugs and their long-term detrimental effects only fuels the fire. From primary school, awareness campaigns should be conducted to inform young minds. Proper knowledge can help in reducing misuse in a greater amount. A helpline should be set up for students to report suspicious drug activity maintaining a drug-free campus. The first new federal drug policy in 40 years was The Comprehensive Addiction and Recovery Act (CARA), which was signed into law in 2016; CARA provides six foundations required for a full, organized solution to the opioid crisis: (1) prevention, (2) care, (3) recovery, (4) law enforcement, (5) overhaul of criminal justice, and (6) reversal of overdose ${ }^{11}$.

In India and other South Asian countries, a major problem among medical students is substance abuse with around one in five Indian medical students are affected by different types of substance abuse, and among those one of the most common is opioids. Medical students are the future of prescribing opioids, and thus their addiction is a matter of great concern and irony. There might be a couple of reasons but the most common ones identified are stress and psychological weakness. Medical students are mostly detached from the common world due to the difficult career path and with continuous pressure regarding their future, these matters pull them into substance abuse like opioids. So, the solution here is to set up destressing programs for them along with easing their workload. Stress relief programs and psychological supports are 
important to reduce substance abuse among medical students in India, Pakistan, and other South Asian Countries.

Financial pressure, one of the key fields of burden, is likely to be faced by families because of the lack of patient income and the use of funds to purchase substances on which they rely. The Centers for Disease Control and Prevention reports that in the United States alone, the overall "economic burden" of prescribing drug diversion is $\$ 78.5$ billion a year, covering hospital costs, lack of productivity, treatment of addiction, and intervention in criminal justice. The conditions in south Asian countries are worse than the USA. As the main chain suppliers of opioids are South Asian Countries, so the situation, as well as the economic burden in the south asian countries, are quite high. Due to unavailability of data, it is tough to accurately predict the financial strain but it is likely to be much higher due to a large segment of the population being young and hence involved in drug abuse.

In a bid to curtail further growth of this pandemic, a strong legal and clinical framework should be set up to regulate the open pharmaceutical market. Opiate medications should be registered under brand names, and prescription of such medications should be limited to government hospitals and registered private hospitals, all of which should be supervised by a regulatory body. All dispensing of opiates should only be carried out with prescriptions and in limited doses. With a national priority on minimizing opioid prescription, improving administrative oversight, and enacting strict prescribing guidelines, legislators have reacted to the epidemic. As stated by the Quintiles IMS Institute, these and other steps tend to have the desired impact of bringing down dispensed opioid prescriptions, which plunged for 2 consecutive years, dropping 2.7 percent in 2015 and 1.7 percent in $2016 .^{12}$

120 So, it is high time to solve these problems. Physicians should prescribe opioids very carefully after knowing the history of abuse and also after checking pain severity and urine opioid amount. Government has a very crucial role. Respective governments should control the open selling of opioids and also the promotions of pharma companies. Strict laws, rehabilitations, punishments should be added behind the abusing. Different NGOs should conduct awareness programs in the community and the schools. Different community health workers should be trained on how to 
give naloxone and how to treat the overdose cases. Psychological supports, Stress Relieving programs should be conducted.

It can be concluded that for the last 2 decades, the opioid crisis has been blamed for hundreds of thousands of lives lost, and millions more patients and their families have been adversely affected by prescription opioid addiction or violence. Indirect casualties also entail losses due to addict's premature death, either due to normal course of sickness, accident, or addict suicide, leading to increased family burden. The substance abuse is a rampant pandemic raging throughout the globe with South Asian countries bearing the brunt of having produced, traded, and used drugs. Opioid abuse has many reasons and to curtail further growth of this problem, a region-wide collaboration is required to legally uproot the opioid mafia with emphasis on legislation on prescription opioids and their use, a crackdown on the organized crime syndicates propelling drugs, and most importantly- setting up awareness campaigns for the vulnerable and rehab centers for the victims looking for a way out.

\section{References:}

1. Wdr.unodc.org. 2021. Impact of drug use on health. [online] Available at: <https://wdr.unodc.org/wdr2020/field/WDR20_Booklet_2.pdf> [Accessed 20 February 2021].

2. opioid overdose. 2020. [online] Available at: <https://www.who.int/news-room/factsheets/detail/opioid-overdose> [Accessed 20 February 2021].

3. SAMHSA (Subst. Abuse Ment. Health Serv. Adm.). 2010. Center for Behavioral Health Statistics and Quality. Treatment Episode Data Set (TEDS): 2007. Discharges from Substance Abuse Treatment Services. DASIS Ser.: S-51, HHS Publ. No. (SMA) 10-4479. Rockville, MD: SAMHSA available at< https://www.samhsa.gov/data/sites/default/files/TEDS2011St_Web/TEDS2011St_Web/T EDS2011St_Web.pdf> [Accessed on 20 February 2021]

4. SAMHSA (Subst. Abuse Ment. Health Serv. Adm.). 2011. CAI Specifications for Programming in English: 2012 National Survey on Drug Use and Health. Rockville, MD: SAMHSA. [online] available at $<$ https://www.icpsr.umich.edu/icpsrweb/DSDR/studies/34933?keyword\%5B0\%5D= 

February 2021]

5. Colledge, S., Peacock, A., Leung, J., Larney, S., Grebely, J., Hickman, M., Cunningham, E., Trickey, A., Stone, J., Vickerman, P. and Degenhardt, L., 2019. The prevalence of non-fatal overdose among people who inject drugs: A multi-stage systematic review and meta-analysis. International Journal of Drug Policy, 73, pp.172-184. PMID: 31351755.

6. Majid, Z., Tanveer, M., Ali Asghar, S., Tahir, F., Minhaj, A., Khan, H., Sialvi, T., Mahmood, S., Qadar, L. and Imtiaz, F., 2019. Opioids Use and Abuse: Prescription Practice, Attitude, and Beliefs among Doctors of Karachi. Cureus,.PMID: 31572638; PMCID: PMC6760877.

7. RK, S., 2018. Pakistan's opioid crisis. [online] Thenews.com.pk. Available at: $<$ https://www.thenews.com.pk/print/342951-pakistan-s-opioidcrisis.> [Accessed 20 February 2021].

8. Ambekar, A., Chadda, R., Khandelwal, S., Rao, R., Mishra, A. and Agarwal, A., 2019. Magnitude of substance use in India. [ebook] New Delhi: MINISTRY OF SOCIAL JUSTICE AND EMPOWERMENT GOVERNMENT OF INDIA. Available at: $<$ http://socialjustice.nic.in/writereaddata/UploadFile/Survey\%20Report.pdf> [Accessed 21 February 2021].

9. Perlman, D. and Jordan, A., 2018. The Syndemic of Opioid Misuse, Overdose, HCV, and HIV: Structural-Level Causes and Interventions. Current HIV/AIDS Reports, 15(2), pp.96-112.

10. SAMHSA (Subst. Abuse Ment. Health Serv. Adm.). 2009. Trends in Nonmedical Use of Prescription Pain Relievers: 2002 to 2007. NSDUH Rep. Rockville, MD: SAMHSA $<$ https://www.samhsa.gov/data/sites/default/files/NSDUH\%20Report_RxDrug\%20Nonme dicalTrends.pdf > [Accessed 21 February 2021]

11. Congress.gov. 2016. Text - S.524 - 114th Congress (2015-2016): Comprehensive Addiction and Recovery Act of 2016 [CLARA], PL 114-198. [online] Available at: $<$ https://www.congress.gov/bill/114th-congress/senate-bill/524/text> [Accessed 21 February 2021]. 
189

190

191

192

193

194

195

12. Lowes, R., 2017. Message Heard? Pain Med Prescribing Down Second Year in Row. [online] Medscape. Available at: 〈https://www.medscape.com/viewarticle/879514〉 [Accessed 21 February 2021]. 